\title{
High energy pulsed laser deposition of ohmic tungsten contacts on silicon at room temperature
}

\author{
D. Dellasega ${ }^{1}$, M. Bollani ${ }^{2,}$,, L. Anzi ${ }^{3}$, A. Pezzoli ${ }^{1}$, D. Chrastina ${ }^{3}$, A. Gulinatti ${ }^{4}$, G. Irde $^{5}$, R.
} Sordan $^{3}$, M. Passoni ${ }^{1}$, and S.M. Pietralunga ${ }^{6}$

1 Dipartimento di Energia, Politecnico di Milano, via Ponzio 34/3, 20133 Milan, Italy

2 L-NESS, IFN-CNR, Via Anzani 42, 22100 Como, Italy.

3 L-NESS, Dipartimento di Fisica, Politecnico di Milano, Polo di Como, Via Anzani 42, 22100 Como, Italy

4 Dipartimento di Elettronica, Informazione e Bioingegneria, Politecnico di Milano, via Ponzio 34/5, 20133 Milan, Italy

5 Dipartimento di Fisica, Politecnico di Milano, Piazza Leonardo da Vinci 32, 20133 Milano, Italy

6 IFN-CNR, Piazza Leonardo da Vinci 32, 20133 Milano, Italy

* corresponding author: monica.bollani@ifn.cnr.it

\begin{abstract}
Tungsten-on- $\mathrm{n}^{+}$silicon ohmic contacts were obtained by depositing $100 \mathrm{~nm}$-thick $\mathrm{W}$ coatings on silicon substrates using pulsed laser deposition at room temperature, without native oxide removal. The high energy of the impinging species (about 10-100 eV per atom) led to sputtering phenomena and to the implantation of $\mathrm{W}$ atoms through the Si oxide. W coatings were characterized, asdeposited and after performing rapid thermal annealing steps. The morphology and crystallinity were characterized by scanning electron microscopy, X-ray diffraction and reflectometry. The interdiffusion of $\mathrm{W}$ and $\mathrm{Si}$ was shown by scanning Auger microscopy. The ohmic character of the contacts and contact resistance were investigated by the transfer length method. Fast annealing at moderate temperatures $\left(450{ }^{\circ} \mathrm{C}\right)$ remarkably improved contact performance without significant variation of the features of either $\mathrm{W}$ film or Si substrates. The ohmic character of the contact was preserved even after annealing at high temperature $\left(1000^{\circ} \mathrm{C}\right)$ at which a complete interdiffusion of $\mathrm{Si}$ into the $\mathrm{W}$ film takes place.
\end{abstract}




\section{Introduction}

Tungsten is used in microelectronics since decades, to provide metallic contact on $\mathrm{Si}$ and wide band-gap semiconductors such as silicon carbide [1-4]. It features complementary metal oxide semiconductor compatibility, a high melting temperature, useful to sustain the chemical vapor deposition (CVD) processes typical of very large-scale integration (VLSI) technology and to guarantee the thermal stability of the contact, high mechanical and chemical resistance as well as high adhesion and wettability on silicon. Specifically, the latter properties make it a material of choice for the metallization of high aspect ratio patterns and through-silicon vias (TSV) [5,6]. It also features the best matching of thermal expansion coefficient with Si. Its electrical resistance is comparable with $\mathrm{Al}, \mathrm{Cu}$ and noble metals. In addition, thanks to its low electron mean free path (19 $\mathrm{nm}$ ), in the case of very thin films, W exhibits lower resistivity compared with other metals, like e.g. $\mathrm{Cu}[7]$.

The metal-semiconductor abrupt junction at Tungsten on (001) Silicon surface is characterized by Schottky voltage barrier heights around $0.7 \mathrm{eV}$ and $0.5 \mathrm{eV}$, respectively in case on $n$-type and $p$ type doped Si $[8,9]$. Due to these high values, in the case of pure W-Si system an ohmic contact can be established only with the contribution of quantum tunneling effects. Tunneling probability and, as a consequence, the value of contact resistivity for the ohmic contacts depend in turn on the width of the voltage barrier, which is a function of the dopant concentration in Si [10]. Only at very high doping concentrations, higher than $10^{20} \mathrm{~cm}^{-3}$, the establishment of a reliable tunnel current occurs [11].

To overcome this problem at lower doping levels several recipes have been developed to obtain $\mathrm{W}$ on-Si ohmic contacts, which mostly rely on depositing $\mathrm{W}$ either in alloys or in metallic multilayers, such as WN/W/PtSi/Si or W/TiN/TiSi/Si structures. Refractory metal silicides are considered as alternative materials for low-resistance ohmic contacts and interconnects on Silicon in VLSI systems [12]. Tungsten silicide, specifically $\mathrm{WSi}_{2}$, is a metallic compound, forming a barrier with Silicon substrate, which strongly depends on the conditions of $\mathrm{W}$ deposition and subsequent annealing. Reported values for the height of the $\mathrm{WSi}_{2} / \mathrm{n}$-Si barrier range from $0.68 \mathrm{eV}$ to $0.86 \mathrm{eV}$ [13]. Tungsten silicides may be either directly deposited, or formed by a post-deposition annealing step at high temperature (above $650^{\circ} \mathrm{C}$, see $[14,15]$ ). W silicides have beneficial effects by promoting the adhesion of the $\mathrm{W}$ metallic layer on Si. Moreover they act as a diffusion barrier for the silicon and ensure a higher conductivity compared with polysilicon [4,16-18] and favor the ohmic contact.

It would be of technological interest to diminish the number of process steps necessary to obtain W on Si ohmic contacts by depositing W directly on Si. To overcome the problem of Si doping, a W$\mathrm{Si}$ intermixed zone can be created at the interface using high energy species. Ion-assisted metal deposition on Si results in graded composition interfaces, leading to non-rectifying low-resistance contacts, as has been demonstrated at a local scale by direct writing of tungsten contacts using focused ion beam (FIB) assisted techniques [19-21]. Therefore, differently from the W multilayered systems, the direct deposition of $\mathrm{W}$ on $\mathrm{Si}$ may lead to the formation of ohmic contacts without the need for thermal annealing steps. This, in turn, would be beneficial with respect to the total thermal budget of the production process. Moreover, high temperature processing steps may induce the migration of the dopant species, thus affecting the performances of the device. 
One further major issue related to the fabrication of ohmic W-Si junctions is the presence of native oxide on Si surface. The presence of interfacial oxide significantly retards the formation of W-Si compounds, and leads to the absence of a good electrical contact [11,14,22]. During the deposition of $\mathrm{W}$ by chemical vapor deposition (CVD) the grow rate and even the crystallographic phase of the deposited $\mathrm{W}$ film are influenced by the thickness of native silicon oxide [23]. If a barrier to $\mathrm{WSi}_{2}$ formation exists due to the native oxide, incomplete substrate covering by deposited $\mathrm{W}$ occurs and non-uniform layer is formed [14]. Due to the difference in coefficient of thermal expansion between $\mathrm{W}$ and Si oxide (respectively 4.5 and $0.55 \mu \mathrm{m} / \mathrm{m} \mathrm{K}$ ) stress, delamination or even detachment of W film may happen during the deposition procedure if native silicon oxide has not been removed [24]. Finally this issue becomes important whenever very high aspect ratio structures are considered, as in TSV connections, where, however, complete oxide removal is hardly achieved [25]. For all these reasons, a process step of native oxide removal usually needs to be performed before depositing the $\mathrm{W}$ coating, to assure reliability and uniformity in deposition and to improve contact performances.

W films are deposited by one out of several different techniques, depending on the application envisaged. Magnetron sputtering [1,3], CVD [26,27], and e-beam evaporation [28,29] are mostly used. In the present work, tungsten contacts have been deposited by Pulsed Laser Deposition (PLD) technique on $(001) \mathrm{n}^{+} \mathrm{Si}$ substrates. Specifically, in this work we show that, by directly depositing $\mathrm{W}$ on Si contacts using PLD, ohmic electrical character can be obtained, starting from room temperature conditions, without requiring extremely high doping levels for the Si substrate and without the need to remove the native oxide layer at Si surface.

PLD is an out-of-equilibrium physical vapor deposition technique which, although mainly exploited for the deposition of metallic oxides [30], has proven to be also very effective in depositing pure metallic films (e.g. Rh films [31]). By exploiting the non-equilibrium features of the PLD process, metallic tungsten film structures ranging from nanocrystalline columnar to amorphous-like and porous can be grown [32]. The proper thermal annealing of amorphous-like $\mathrm{W}$ may even induce the nucleation and growth of tungsten-oxide nanowires [33]. During the PLD process, when a laser fluence higher than $10 \mathrm{~J} / \mathrm{cm}^{2}$ is used, ions and atoms impinge on the sample surface with energies of about $10-100 \mathrm{eV}[34,35]$, what may lead to sputtering of the surface and implantation and diffusion phenomena in the substrate [36,37]. Therefore, similarly to what occurs in the case of FIB-assisted W deposition, PLD could contribute to improve the contact features of W directly deposited on Si on a large, macroscopic, scale. The high energy regime of PLD would allow the deposition of adherent coatings and the thinning or removal of native oxide at surface. The advantage would be twofold: to reduce the disadvantages related to the presence of oxide and, at the same time, to avoid the need for a dedicated removal step in the production process. In addition, the implantation of $\mathrm{W}$ atoms in $\mathrm{Si}$ surface could influence the formation of $\mathrm{WSi}_{2}$ layer after annealing, thus improving the performances and stability at high temperature. Thanks to the high energy of the impinging species, deposition by PLD might be suitable to grow metal contacts onto high aspect ratio channels and patterned surfaces. Actually, recent studies on black silicon solar cells, that rely on deep roughening of the top surface to enhance sunlight absorption [38,39], prove that $\mathrm{Ti} / \mathrm{Pd} / \mathrm{Ag}$ ohmic contacts deposited by PLD onto the rough surface outperform those deposited by other techniques (sputtering, thermal evaporation, direct printing) [39]. On the other side, PLD should be strictly taken as a prototypical technique, suffering of issues related to the limited deposition area and the possible presence of droplets. In the case deposition at high energies turns out to be a key asset to 
reach desired features of the metallic contacts, large scale deposition processes can eventually be devised, by turning to more industrially scalable high energy techniques, such as High Power Impulse Magnetron Sputtering with a proper bias voltage [40].

We deposited W on $\mathrm{Si}$ contacts by PLD at room temperature and performed Rapid Thermal Annealing (RTA) steps at various temperatures, up to $1000^{\circ} \mathrm{C}$. Systematic electrical and structural characterizations have been carried out after annealing from room temperature up to $1000^{\circ} \mathrm{C}$ observing the silicide formation and Si interdiffusion.

\section{Experimental details}

W coatings were deposited by PLD [32], by exploiting the second harmonic of a Nd:YAG laser at $\lambda=532 \mathrm{~nm}$, repetition rate of $10 \mathrm{~Hz}$, temporal pulse duration of 5-7 ns and energy per pulse of $740 \mathrm{~mJ}$. The spot area of the impinging laser on the target was about $5 \mathrm{~mm}^{2}$ and the measured fluence $\sim 14.5 \mathrm{~J} / \mathrm{cm}^{2}$. The species ablated from the $\mathrm{W}$ target expanded in the deposition chamber, at a base pressure of $3 \times 10^{-3} \mathrm{~Pa}$. In this pressure regime the main important gas contaminant is oxygen. The expanding species, mainly single atoms under the conditions of ablation above described, were collected on the substrate positioned $70 \mathrm{~mm}$ away from the target. Thanks to the use of a sample holder which keeps the substrate in motion during the deposition, and to an off-axis deposition scheme [31], the deposition of a uniform $\mathrm{W}$ film was achieved. In the present deposition conditions, the growth rate turns out to be $14.3 \mathrm{~nm} / \mathrm{min}$. Film specimens $50 \mathrm{~nm}$ thick were deposited on plain Si substrate, for structural characterization. W film $100 \mathrm{~nm}$ thick were deposited on $\mathrm{n}^{+}$type Si for the electrical characterization of the contacts. After deposition, $\mathrm{W}$ films and contacts were subjected to RTA in $\mathrm{N}_{2}$ atmosphere at $200^{\circ} \mathrm{C}, 450^{\circ} \mathrm{C}, 850^{\circ} \mathrm{C}$ and $1000^{\circ} \mathrm{C}$, with a dwell time of $5 \mathrm{~min}$.

Film morphology has been characterized by a Zeiss Supra 40 field emission scanning electron microscope (SEM) with an accelerating voltage of $3-5 \mathrm{kV}$. The film crystalline structure has been analyzed by X-ray diffraction (XRD) and reflectivity (XRR) using a PANalytical X'Pert PRO MRD $\mathrm{X}$-ray diffractometer (monochromatic $\mathrm{Cu} \mathrm{K} \alpha 1$ radiation, $\lambda=0.1540562 \mathrm{~nm}$ ). Local compositional analysis in depth profiling of the Si-W interface region was performed by UHV Scanning Auger Micro-spectroscopy (SAM) (PHI 660). Depth profiling was performed by sputtering the W coating with Argon ion gun $(\mathrm{V}=4 \mathrm{kV}, \mathrm{I}=2 \mu \mathrm{A})$. The content in $\mathrm{Si}$ and $\mathrm{W}$ at exposed surface was rated by measuring the Silicon LMM Auger peak at $96 \mathrm{eV}$ and Tungsten NNN peak at $180 \mathrm{eV}$. Oxygen content was also estimated, by counting the $\mathrm{O} \mathrm{KLL}$ line at $510 \mathrm{eV}$, while checking for the content of Carbon contaminant by its KLL line at $250 \mathrm{eV}$. Measurements were taken at $\mathrm{V}=3 \mathrm{kV}$ of accelerating voltage, $\mathrm{I}=30 \mathrm{nA}$ of electron beam current and with an energy resolution of $\Delta \mathrm{E} / \mathrm{E}=$ $1 \%$. Under present experimental conditions, depth sensitivity of Auger analysis is between 1 and 2 $\mathrm{nm}$, as limited by electron effective attenuation length, calculated using the NIST SRD 82 database software [41].

For the W-on-Si contacts electrical characterization $\mathrm{n}^{+}$type (As-doped, resistivity $1-4 \mathrm{~m} \Omega \cdot \mathrm{cm}$ ) $\mathrm{Si}$ (001) substrates were used. Native oxide, of estimated thickness around $0.7-1.5 \mathrm{~nm}$ [42], was not removed from the Si surface. A sequence of $\mathrm{W}$ rectangular electrodes was fabricated by optical lithographic and lift-off procedure, in a typical transfer length method (TLM) structure used to characterize $n$ or $p$ type $\mathrm{Si}$ or n-p type Si-Ge films as reported in [43] [44] the TLM is, indeed, an useful approach to describe the planar contacts between a metal and semiconductor material. The sequence of definition of the $\mathrm{W}$-on-Si electrodes is illustrated in Figure 1. The thick resist film, prepatterned by optical lithography, was coated with W PLD films, $100 \mathrm{~nm}$ thick. Then a lift-off step 
in acetone was performed to remove the resist and to define the electrodes. In the resulting TLM geometry, each electrode measured $48 \mu \mathrm{m} \times 200 \mu \mathrm{m}$ and the inter-electrode distance increased from 15 to $65 \mu \mathrm{m}$ (see Figure 1). I-V characteristics of the W on Si system were measured and specific contact resistivity $\left(\rho_{C}\right)$ was extracted using the TLM approach on the patterned W contacts [45].

\section{Results}

Film morphology after the different annealing treatments was assessed by SEM. As shown in Figure 2a (not-annealed film), the deposited $\mathrm{W}$ film is very smooth and compact, thanks to the high energy of the impinging species and the nanocrystalline domains are clearly visible. The annealing at $450^{\circ} \mathrm{C}$ does not significantly affect the morphology of the film. Also, the dimensions of the crystallite domains are unchanged. The thermal treatment at $850^{\circ} \mathrm{C}$ results in the development of a completely different morphology. The surface appears much rougher and irregular made of nanoaggregates. The annealing at $1000^{\circ} \mathrm{C}$ induces the same kind of morphology although the nanoaggregates are more defined and nano-crystalline facets start to appear.

Figure 3 compares measured XRR spectrum of the deposited W film, $50 \mathrm{~nm}$ thick, with a dynamical simulation [46], vertically offset for clarity. The simulation (reduced chi-squared: 0.0035) specifies a film thickness of $52.5 \mathrm{~nm}$, with a surface roughness of $\sim 0.9 \mathrm{~nm}$. The agreement in critical angle between the measurement and the simulation indicates that the density of the deposited layer is equal to that of $\mathrm{W}$, i.e. that the deposited film is compact and not porous.

Figure $4 \mathrm{a}$, shows a wide $2 \theta$ scan XRD analysis at grazing incidence for the $\mathrm{W}$ film (50 nm thick) following annealing at different temperatures. Only the reflections related to the crystalline $\alpha-\mathrm{W}$ phase (and some asymmetric Si reflections from the substrate) are visible. The $\mathrm{W}$ film annealed at $450^{\circ} \mathrm{C}$ behaves similarly to the as-grown material without annealing (not shown here). On annealing at $850^{\circ} \mathrm{C}$ the diffraction pattern changes completely to that of tetragonal $\mathrm{WSi}_{2}$ with no carbides or oxides of tungsten visible, but then there is no further change on annealing up to $1000^{\circ} \mathrm{C}$. In Figure $4 \mathrm{~b}$ a detailed $2 \theta-\omega$ scan around the $\alpha-\mathrm{W}(110)$ peak is shown. The results confirm the close resemblance of the diffraction patters of the as-grown $\mathrm{W}$ film and of the specimen annealed at $450^{\circ} \mathrm{C}$, suggesting that the material is already heated by the PLD process and that the annealing at $450^{\circ} \mathrm{C}$ would not affect the crystallinity of $\mathrm{W}$, because of the short dwell time and low temperature. On the other hand, both in the case of the as-grown film and material annealed at $450^{\circ} \mathrm{C}$, a weak broad peak at $47^{\circ}$ is evident, which may correspond to the presence of a small amount of $\mathrm{WO}_{3}$. XRD cannot, however, confirm the presence or absence of a thin layer of amorphous $\mathrm{SiO}_{2}$ at the W/Si interface. The complete transformation of W $50 \mathrm{~nm}$ thick into $\mathrm{WSi}_{2}$ after a so short annealing (dwell time 5 minutes) at $850^{\circ} \mathrm{C}$ is an indirect proof of a deep change in the properties of the W-Si interface. In fact as reported in [14] the presence of the native oxide layer should have prevented the diffusion of $\mathrm{Si}$ in the $\mathrm{W}$ film.

To better address this point, elemental analysis across the W-Si interface for W films $100 \mathrm{~nm}$ thick was performed by depth profiling (by means of sputtering) SAM. Figure 5 shows the compositional profile taken in a line across the sputtered region, for the not-annealed sample. W, Si and O relative concentrations across the W-Si interface, from $20 \mathrm{~nm}$ in the bulk of the $\mathrm{W}$ film to $70 \mathrm{~nm}$ in the bulk of Si substrates, are shown. The depth of the sputtered zone was calibrated by profilometry. It is worth to note that the depth sensitivity of SAM is about $1 \mathrm{~nm}$ and thus the $\mathrm{O}$ concentrations are 
related to the surface contamination. The impurities may be related to the measurement setup or incorporated in the $\mathrm{W}$ film during the deposition. A significant implantation of $\mathrm{W}$ into the $\mathrm{Si}$ substrate has taken place during PLD generating an intermixing zone of about 20-30 nm, due to the high energy of the impinging $\mathrm{W}$ species. It is interesting to note that there is no variation in the oxygen signal at the W/Si interface. The state of oxidation of Si can be verified by checking the spectral shape of the Si Auger line at $96 \mathrm{eV}$. The Si spectrum taken all over the interface region of the sample at RT is reported in the inset of Fig.5 and corresponds to unoxidized crystalline $\mathrm{Si}$, showing that the native silicon oxide layer has been removed during the PLD process.

The evolution in depth of the $\mathrm{W} / \mathrm{n}^{+} \mathrm{Si}$ compositional ratio is reported in Figure 6, at room temperature and after $850{ }^{\circ} \mathrm{C}$ thermal annealing. In the as-deposited sample $\mathrm{W}$ concentration is $100 \%$ in the $\mathrm{W}$ film and rapidly decreases going into the Si substrate generating an intermixing zone of $20-30 \mathrm{~nm}$. The presence of implanted $\mathrm{W}$ in $\mathrm{Si}$ is likely to occur during the PLD process at laser fluences higher than $10 \mathrm{~J} / \mathrm{cm}^{2}$ [36]. On the contrary, in the case of $\mathrm{W}$ films deposited by sputtering on Si-based substrates, ohmic contact is possible only after high temperature annealing that leads to the formation of $\mathrm{W}$ inter-metallics [4]. RTA at $850^{\circ} \mathrm{C}$ does not affect the composition of the intermixing zone under the $\mathrm{Si}$ surface. In fact, the differences in relative composition are negligible. But the RTA at $850^{\circ} \mathrm{C}$ increases Si concentration (W signal decreases) in the $\mathrm{W}$ film, which is an indication of $\mathrm{Si}$ interdiffusion up to the surface. The result of RTA at temperatures higher than $850^{\circ} \mathrm{C}$ results in a diffusion of $\mathrm{Si}$ from the substrate up to the surface of the film corresponding to the formation of $\mathrm{WSi}_{2}$. It is interesting to note that due to the increased thickness of the W film, $100 \mathrm{~nm}$ instead of $50 \mathrm{~nm}$, the short annealing time (5 min.) did not allow the diffusion of a sufficient amount of $\mathrm{Si}$ to induce the complete formation of $\mathrm{WSi}_{2}$ as shown in the case of the $\mathrm{W}$ films $50 \mathrm{~nm}$ thick annealed in the same conditions.

I-V characteristics of the W-on-Si system were measured and specific contact resistivity $\left(\rho_{C}\right)$ was extracted using the TLM approach on the patterned $\mathrm{W}$ contacts [45]. Figure 7a) reports the I-V characteristic measured between two electrodes (inter-distance of $25 \mu \mathrm{m}$ ) of the TLM geometry, before performing any additional thermal treatment. The I-V curve is linear in the whole measurement range. Moreover, the linear trend of I-V curve indicates that the native oxide has been modified or is no longer present.

Transport through a native oxide layer of three different thicknesses was simulated with a direct tunneling model, Sentaurus Device from Synopsys [47], in Figure 7 b). The simulated I-V characteristics are all strongly nonlinear. The linearity of the experimental I-V characteristic, in this case, can be ascribed to the implantation of $\mathrm{W}$ atoms in the silicon substrate as shown in the Auger analysis. The W-Si intermixing zone allows the establishment of an ohmic contact between the metal and semiconductor.

In Figure 8 a) the I-V characteristics of the TLM resistor after thermal annealing are reported. The total resistance $\left(R_{T}\right)$ of the contact can be extracted from the slope of $I-V$ curve. The $R_{T}$ can be modeled as the sum of three components:

$$
R_{T}=2 R_{m}+R_{S}+2 R_{C}
$$

where $2 R_{m}$ represents the internal resistance of the two metallic conductors, the $R_{S}$ is the semiconductor resistance and the $2 R_{C}$ represents the contact resistance between the metal and semiconductor for two metallic contacts, as reported in [43]. Typically, $R_{m}$ is negligible when 
compared to the other terms, while the term $R_{S}$ is very small due to the high conductivity of $\mathrm{n}^{+} \mathrm{Si}$. It is evident from Figure 8 a) that there is a significant reduction in $R_{T}$, because of thermal annealing. From what stated before, we can conclude that this is a consequence of a lowering in resistivity of the contacts as the annealing time is too small to affect the dopant distribution in Si. Due to strong dependence of the $R_{C}$ on the contact area (A), it is appropriate to introduce a specific contact resistance $\rho_{C}\left(\Omega \mathrm{cm}^{2}\right)$ :

$$
R_{C}=\frac{\rho_{C}}{A}
$$

The different values of the $R_{C}$ obtained by TLM measurements can be extracted by the characteristics in Figure 8a and the specific contact resistances $\rho_{C}$ as a function of the annealing temperature are plotted in Figure 8b.

Experimental I-V curves shown in Fig. 8a are linear and symmetrical, indicating ohmic electrical conduction and, specifically, the ohmic behavior of the W/Si contacts.

The values for $\rho_{C}$, measured in the sample before and after annealing at $200^{\circ} \mathrm{C}\left(\rho_{C} \sim 10^{-2} \Omega \cdot \mathrm{cm}^{2}\right)$ are very high compared to $\mathrm{W} / \mathrm{Si}$ ohmic contacts deposited without native oxide $\left(10^{-5}-10^{-}\right.$ ${ }^{6} \Omega \cdot \mathrm{cm}^{2}$ )[11]. The introduction of a $5 \mathrm{~min}$ annealing step at moderate temperatures (up to $450^{\circ} \mathrm{C}$ ) results in a lowering of $\rho_{C}$ by one order of magnitude $\left(10^{-3} \Omega \cdot \mathrm{cm}^{2}\right)$, without inducing modifications in the crystallinity or stoichiometry of the deposited W layer, as shown by the XRD and Auger characterizations. A similar change in resistivity in the same temperature range has been found in $\mathrm{W}$ layers produced by FIB assisted CVD [19]. Ion bombardment produces an intermixing region between $\mathrm{W}$ and $\mathrm{Si}$ that is very sensitive to temperature variations [20]. The same temperature sensitivity has been found in the deposition of Fe-Si metallic contacts by PLD on silicon [48]. In that case the establishment of the ohmic contact is found to be dependent on the Fe-Si deposition temperature, promoting the diffusion of $\mathrm{Fe}$ atoms in the first substrate layers. After 5 minutes of annealing at $850^{\circ} \mathrm{C}$ or $1000^{\circ} \mathrm{C}$ the complete interdiffusion of $\mathrm{Si}$ in the $\mathrm{W}$ layer takes place, as shown in Figure 6. Correspondingly, the values for $\rho_{C}$ decrease by almost one additional order of magnitude if compared with $\mathrm{W}$ annealed at $450{ }^{\circ} \mathrm{C}$, reaching $\sim 4 \cdot 10^{-4} \Omega \cdot \mathrm{cm}^{2}$. Table 1 reports a comparison of the experimental $\rho_{C}$ values obtained in this work with those featured by direct ohmic W/Si contacts fabricated using several deposition techniques, with and without thermal annealing process. Temperature and duration of the annealing is also reported. Results are given as order-ofmagnitude evaluations. Tungsten coatings deposited using PLD, both at RT and annealed at low temperature, perform equivalently to W/Si contacts fabricated by FIB (respectively $10^{-2} \Omega \cdot \mathrm{cm}^{2}$ and $10^{-4} \Omega \cdot \mathrm{cm}^{2}$ ) and measured on structured contacts in a Cross-bridge Kelvin resistor scheme. Resistivity of RF-sputtering on plane substrates is lower compared with PLD, being around (10$\left.{ }^{6} \Omega \cdot \mathrm{cm}^{2}\right)$. CVD exhibits even lower contact resistances $\left(10^{-7}-10^{-8} \Omega \cdot \mathrm{cm}^{2}\right)$ thanks to the selective removal of native oxide directly performed at the first stages of the deposition. It is worth to note that $\mathrm{W}$ contacts deposited by CVD are obtained using a Si substrate with a doping concentration of

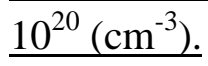

Ohmic I-V characteristics, as experimentally verified in the present case (see Figs. 7a and 8a), can be justified by a lowering of the voltage barrier that is established between metal and semiconductor. The electrical conduction across a metal--n-type semiconductor junction can be described with the aid of the sketch in Figure 9. At equilibrium conditions, in the Schottky limit 
case ( low density of interfacial defects) [49] a voltage barrier $\phi_{B n}$ develops at the interface as $q \phi_{B n}=\left(q \phi_{m}-\chi_{s}\right)$, where $q \phi_{m}$ is the metal work function and $\chi_{s}$ is the electron affinity for semiconductor. Vacuum energy level $E_{v a c}$ is also indicated, as well as Fermi energy levels, respectively named $E_{F m}$ for the metal and $E_{F n}$ for the semiconductor. On the semiconductor side, $q \phi_{F}$ is the distance in energy between the conduction band minimum and the Fermi level, according to semiconductor doping level. In dependence on the value of $\phi_{B n}$ and on doping level, three different charge transport regimes can be identified to contribute to ohmic conduction [10][49]. In case of light semiconductor doping, the ohmic behavior of the contact is provided by thermionic emission of hot ballistic electrons over the barrier (TE regime). If very high doping levels are considered, close to degeneracy, the leading mechanisms is the emission of electrons by quantum tunneling across the barrier, driven by applied electric-field (Field-Emission FE regime). At intermediate doping levels charge conduction can be modelled by a combination of the two regimes (Thermionic-Field-Emission TFE model). The Padovani-Stratton parameter is an equivalent energy defined as:

$E_{00}=\frac{e \hbar}{2} \sqrt{\frac{N_{d}}{m^{*} \epsilon}}$, where $\mathrm{Nd}$ is the donor concentration, $\hbar$ the reduced Plank constant, $\mathrm{m}^{*}(\cong 0.5 \mathrm{~m})$ the effective mass of electron and $\epsilon$ the dielectric permittivity of $\mathrm{Si}$. The ratio $E_{00} / k T$ measures the relative importance of the electron tunneling mechanism over the thermionic emission [Yu] and defines the regime of conduction between FE $\left(E_{00} / k T \gg 1\right)$ and TE $\left(E_{00} / k T \ll 1\right)$. Values $E_{00} /$ $\underline{k T \sim 1}$ indicate the intermediate TFE condition. The resistivity range of the $\mathrm{n}+\mathrm{Si}$ substrates used (1$4 \mathrm{~m} \Omega \mathrm{cm})$ corresponds to donor doping densities $1.6 \div 8 \cdot 10^{19} \mathrm{~cm}^{-3}[10]$ and to $\frac{E_{00}}{k T}=0.95 \div$ 2.12 at $\mathrm{T}=298 \mathrm{~K}$, so that electrical conduction across the barrier is TFE dominated [49].

Although in the present case an intermixed W-Si region is present, we use the model presented above to calculate an equivalent barrier height at the junction. The barrier height $\phi_{B n}$ can be calculated [50] by comparing $\rho_{c}$ values and by assuming Yu's TFE theory [49]. The obtained results are displayed in Table 2 in correspondence to the different annealing conditions of the W-Si system at low temperature, i.e. no silicide formation. If we compare the values obtained for $\phi_{B n}$ with the Schottky limit case, we find a good agreement. A value $q \phi_{B n}=\left(\phi_{m}-\chi_{s}\right)=0.55 \mathrm{eV}$ can be estimated considering a work function value $q \phi_{m}=4.6 \mathrm{eV}$ for polycrystalline W film [51] and $\chi_{s}=4.05 \mathrm{eV}$ for electron affinity of $\mathrm{Si}$ [52]. However, in the present case of film growth by PLD the high energy of deposited W species will induce the formation of defects in the interfacial region. The presence of defects at the surface of a semiconductor results in the pinning of the Fermi energy level and in the departure from the Schottky limit model [10]. In this frame, the experimental values of about $0.7 \mathrm{eV}$ for voltage barriers at abrupt W/n-Si interfaces are justified, leading to non-ohmic contacts [8,9]. In the PLD case, $\mathrm{W}$ implantation and the formation of an interdiffusion layer also introduce bulk deep intragap defect levels, of both donor and acceptor type $[53,54]$. At extremely high W concentrations, as reached in the intermixing zone, defect levels are likely to merge and to form intragap bands, which may also result in bandgap narrowing (see for instance [10]). Also, the formation of low bandgap WSi ${ }_{x}$ clusters in the intermixing zone is possible [55]. Accordingly, the W-Si system may display a barrier reduction also due to the fact that the bandgap of crystalline $\mathrm{W}$ silicide is about $0.3-0.4 \mathrm{eV}[56]$. A similar result is also suggested by the increase in the amplitude of the reverse current, occurring in the case of thermal interdiffusion of $\mathrm{W}$ into $\mathrm{Si}$ operated in Silicon diodes [53]. In Table 2, the conductivity improvement at $450{ }^{\circ} \mathrm{C}$ 
annealing could be ascribed to an ordering of the alloyed W-Si intermixing region and corresponds to an equivalent barrier height of $0.35 \mathrm{eV}$, if TFE conduction model and all related parameters are kept as valid.

It is worth stating that the mechanisms ruling the barrier height at metal-semiconductor interfaces refer to the physical chemistry of surface at the atomic level and can still be considered as open field of investigation [57]. Mostly, in the present case a proper modelling of the W-Si intermixing zone would evidently be needed for a detailed explanation of electron transport. In fact, the interfacial region is deeply altered by interdiffusion and alloying, so that phenomena such as bandgap reduction, dopant activation and eventually $\mathrm{WSi}_{2}$ crystallization at higher temperatures [58] can contribute both to a reduction in voltage barrier and to variations in the mechanism of ohmic conduction itself.

\section{Conclusions}

In this work we characterized the structural, morphological and electrical properties of $\mathrm{W}$ contacts, deposited at room temperature on $\mathrm{n}^{+} \mathrm{Si}$ wafers using PLD and which turn out as compact, polycrystalline $\alpha-\mathrm{W}$ films. Due to the high energy of the impinging species, interdiffusion of $\mathrm{W}$ in the Si substrate occurs. The metal-semiconductor contact across the $\mathrm{W} / \mathrm{n}^{+} \mathrm{Si}$ interface exhibits an ohmic behavior prior to any thermal annealing step and without the removal of native oxide from the substrate. Fast low temperature annealing lowers contact resistivity without modifying the W film crystallinity, probably due to modifications of the W-Si intermixing region. Rapid thermal annealing at high temperature results in the complete interdiffusion of $\mathrm{Si}$ in the $\mathrm{W}$ film and $\mathrm{WSi}_{2}$ formation, which further reduces the contact resistance. We consider that this deposition technique, due to the high energy of the impinging species, is likely to allow the coverage and the formation of W ohmic contacts on C-MOS compatible complex structures.

\section{Acknowledgements}

The authors acknowledge Project I-Zeb, 7784/2016, III Accordo Quadro CNR -Regione Lombardia for the partial financial support.

\section{References}

[1] P. Petroff, T.T. Sheng, A.K. Sinha, G.A. Rozgonyi, F.B. Alexander, Microstructure, growth, resistivity, and stresses in thin tungsten films deposited by rf sputtering, J. Appl. Phys. 44 (1973) 2545-2554. doi:10.1063/1.1662611.

[2] R.C.C. Sun, Internal stresses and resistivity of low-voltage sputtered tungsten films, J. Appl. Phys. 44 (1973) 1009. doi:10.1063/1.1662297.

[3] R.C. Sun, T.C. Tisone, P.D. Cruzan, The origin of internal stress in low-voltage sputtered tungsten films, J. Appl. Phys. 46 (1975) 112-117. doi:10.1063/1.322250.

[4] J. Rogowski, A. Kubiak, Effects of annealing temperature on the structure and electrical properties of tungsten contacts to n-type silicon carbide, Mater. Sci. Eng. B. 191 (2015) 5765. doi:10.1016/j.mseb.2014.10.015.

[5] T.D. Bestwick, G.S. Oehrlein, Tungsten etching mechanisms in CF4/O2 reactive ion etching plasmas, J. Appl. Phys. 66 (1989) 5034-5038. doi:10.1063/1.343776. 
[6] G. Pares, N. Bresson, S. Minoret, V. Lapras, P. Brianceau, J.F. Lugand, R. Anciant, N. Sillon, Through Silicon Via technology using tungsten metallization, in: 2011 IEEE Int. Conf. IC Des. Technol., IEEE, 2011: pp. 1-4. doi:10.1109/ICICDT.2011.5783204.

[7] D. Choi, K. Barmak, On the potential of tungsten as next-generation semiconductor interconnects, Electron. Mater. Lett. 13 (2017) 449-456. doi:10.1007/s13391-017-1610-5.

[8] M.O. Aboelfotoh, Temperature dependence of the Schottky-barrier height of tungsten on ntype and p-type silicon, Solid State Electron. 34 (1991) 51-55. doi:10.1016/00381101(91)90200-I.

[9] K. Bouziane, M. Mamor, F. Meyer, DC magnetron sputtered tungsten: W film properties and electrical properties of W/Si Schottky diodes, Appl. Phys. A. 81 (2005) 209-215. doi:10.1007/s00339-004-2558-5.

[10] S.M. Sze, K.K. Ng, Physics of semiconductor devices, John wiley \& sons, 2006.

[11] V. Kumar, Fabrication and Thermal Stability of W-Si Ohmic Contacts, J. Electrochem. Soc. 123 (1976) 262.

[12] B.Z. Li, R.G. Aitken, Electrical transport properties of tungsten silicide thin films, Appl. Phys. Lett. 46 (1985) 401-403. doi:10.1063/1.95592.

[13] Y. Itoh, N. Hashimoto, Reaction- Process Dependence of Barrier Height between Tungsten Silicide and n - Type Silicon, J. Appl. Phys. 40 (1969) 425-426. doi:10.1063/1.1657078.

[14] L.D. Locker, C.D. Capio, Reaction kinetics of tungsten thin films on silicon (100) surfaces, J. Appl. Phys. 44 (1973) 4366-4369. doi:10.1063/1.1661965.

[15] M.P. Siegal, W.R. Graham, J.J. Santiago, The formation of thin- film tungsten silicide annealed in ultrahigh vacuum, J. Appl. Phys. 66 (1989) 6073-6076. doi:10.1063/1.343587.

[16] Y. C. Chow, L. Kuan-Yang, and M.-R. Chin, "Plasma nitridated self-aligned tungsten system for VLSI interconnections," Patent Application WO1990000311 A1, Jan. 11, 1990.

[17] W.F. Seng, P.A. Barnes, Calculations of tungsten silicide and carbide formation on SiC using the Gibbs free energy, Mater. Sci. Eng. B. 72 (2000) 13-18. doi:10.1016/S09215107(99)00586-3.

[18] K.C. Saraswat, F. Mohammadi, F. Mohammadi, Work function of WSi<inf>2</inf>, IEEE Electron Device Lett. 1 (1980) 18-19. doi:10.1109/EDL.1980.25213.

[19] J. DeMarco, Anthony J. Melngailis, Contact resistance of focused ion beam deposited platinum and tungsten films on silicon, J. Vac. Sci. Technol. B. 19 (2001) 2543.

[20] H. Langfischer, E. Bertagnolli, Focused ion beam prepared contacts of tungsten to silicon characterized by a cross-bridge Kelvin resistor approach, J. Appl. Phys. 93 (2003) 58275829. doi:10.1063/1.1562738.

[21] A.A. Iliadis, S.N. Andronescu, K. Edinger, J.H. Orloff, R.D. Vispute, V. Talyansky, R.P. Sharma, T. Venkatesan, M.C. Wood, K.A. Jones, Ohmic contacts to p-6H-SiC using focused ion-beam surface-modification and pulsed laser epitaxial TiN deposition, Appl. Phys. Lett. 73 (1998) 3545-3547. doi:10.1063/1.122802.

[22] E. Conforto, P.E. Schmid, Pt-Si reaction through interfacial native silicon oxide layers, Philos. Mag. A. 81 (2001) 61-82. doi:10.1080/01418610108216618. 
[23] H.H. Busta, Film Thickness Dependence of Silicon Reduced LPCVD Tungsten on Native Oxide Thickness, J. Electrochem. Soc. 133 (1986) 1195. doi:10.1149/1.2108818.

[24] T. Narita, "Method of forming conductive layer including removal of native oxide," $\underline{\text { U.S. }}$ Patent 4985372 A, Jan. 15, 1991.

[25] H.-T. Kim, J. Lim, M.-S. Kim, H. Oh, D. Ko, G. Kim, W. Shin, J. Park, Investigation of oxide layer removal mechanism using reactive gases, Microelectron. Eng. 135 (2015) 17-22. doi:10.1016/j.mee.2015.02.025.

[26] K. Suguro, Y. Nakasaki, S. Shima, T. Yoshii, T. Moriya, H. Tango, High aspect ratio hole filling by tungsten chemical vapor deposition combined with a silicon sidewall and barrier metal for multilevel interconnection, J. Appl. Phys. 62 (1987) 1265-1273. doi:10.1063/1.339679.

[27] V. Aubry, F. Meyer, R. Laval, C. Clerc, P. Warren, D. Dutartre, Thermal stability of W on RTCVD Si1-xGex films, Appl. Surf. Sci. 73 (1993) 285-289. doi:10.1016/01694332(93)90181-A.

[28] a. K. Sinha, Control of Resistivity, Microstructure, and Stress in Electron Beam Evaporated Tungsten Films, J. Vac. Sci. Technol. 10 (1973) 436. doi:10.1116/1.1317085.

[29] J.H. Souk, Characterization of electron-beam deposited tungsten films on sapphire and silicon, J. Vac. Sci. Technol. A Vacuum, Surfaces, Film. 3 (1985) 2289. doi:10.1116/1.572866.

[30] D. Dellasega, A. Facibeni, F. Di Fonzo, V. Russo, C. Conti, C. Ducati, C.S. Casari, A. Li Bassi, C.E. Bottani, Nanostructured high valence silver oxide produced by pulsed laser deposition, Appl. Surf. Sci. 255 (2009) 5248-5251. doi:10.1016/j.apsusc.2008.07.170.

[31] A. Uccello, D. Dellasega, S. Perissinotto, N. Lecis, M. Passoni, Nanostructured rhodium films for advanced mirrors produced by Pulsed Laser Deposition, J. Nucl. Mater. 432 (2013) 261-265. doi:10.1016/j.jnucmat.2012.08.046.

[32] D. Dellasega, G. Merlo, C. Conti, C.E. Bottani, M. Passoni, Nanostructured and amorphouslike tungsten films grown by pulsed laser deposition, J. Appl. Phys. 112 (2012) 084328. doi:10.1063/1.4761842.

[33] D. Dellasega, S.M. Pietralunga, A. Pezzoli, V. Russo, L. Nasi, C. Conti, M.J. Vahid, A. Tagliaferri, M. Passoni, Tungsten oxide nanowires grown on amorphous-like tungsten films., Nanotechnology. 26 (2015) 365601. doi:10.1088/0957-4484/26/36/365601.

[34] B. Ilyas, A.H. Dogar, A. Qayyum, The effect of laser irradiance on the charge loss in expanding tungsten plasma, Nucl. Instruments Methods Phys. Res. Sect. B Beam Interact. with Mater. Atoms. 312 (2013) 122-125. doi:10.1016/j.nimb.2013.07.018.

[35] F. Caridi, L. Torrisi, M. Cutroneo, Ionic and atomic characterization of laser-generated plasmas at 5×109W/cm2 pulse intensity, Appl. Surf. Sci. 272 (2013) 6-12. doi:10.1016/j.apsusc.2012.07.042.

[36] M.S. Hussain, A.H. Dogar, A. Qayyum, S.A. Abbasi, Angular distribution of tungsten material and ion flux during nanosecond pulsed laser deposition, Surf. Rev. Lett. 23 (2016) 1650004. doi:10.1142/S0218625X16500049.

[37] A. Perea, J. Gonzalo, C. Budtz-Jorgensen, G. Epurescu, J. Siegel, C.N. Afonso, J. García- 
López, Quantification of self-sputtering and implantation during pulsed laser deposition of gold, J. Appl. Phys. 104 (2008) 084912. doi:10.1063/1.2988145.

[38] H. Savin, P. Repo, G. von Gastrow, P. Ortega, E. Calle, M. Garín, R. Alcubilla, Black silicon solar cells with interdigitated back-contacts achieve $22.1 \%$ efficiency, Nat. Nanotechnol. 10 (2015) 624-628. doi:10.1038/nnano.2015.89.

[39] T. Gimpel, K.M. Guenther, S. Kontermann, W. Schade, Study on contact materials for sulfur hyperdoped black silicon, Conf. Rec. IEEE Photovolt. Spec. Conf. (2011) 002061-002065. doi:10.1109/PVSC.2011.6186358.

[40] A.. Ehiasarian, W.-D. Münz, L. Hultman, U. Helmersson, I. Petrov, High power pulsed magnetron sputtered CrNx films, Surf. Coatings Technol. 163-164 (2003) 267-272. doi:10.1016/S0257-8972(02)00479-6.

[41] C.J. Powell, A. Jablonski, The NIST Electron Effective-Attenuation-Length Database, J. Surf. Anal. 9 (2002) 322-325. doi:10.1384/jsa.9.322.

[42] M. Morita, T. Ohmi, E. Hasegawa, M. Kawakami, M. Ohwada, Growth of native oxide on a silicon surface, J. Appl. Phys. 68 (1990) 1272. doi:10.1063/1.347181.

[43] H.H. Berger, Models for contacts to planar devices, Solid. State. Electron. 15 (1972) 145158. doi:10.1016/0038-1101(72)90048-2.

[44] Y. Chen, M. Ogura, S. Yamasaki, H. Okushi, Ohmic contacts on p-type homoepitaxial diamond and their thermal stability, Semicond. Sci. Technol. 20 (2005) 860-863. doi:10.1088/0268-1242/20/8/041.

[45] D.K. Schroder, Semiconductor Material and Device Characterization, 3rd Editio, WileyIEEE Press, 2006.

[46] D. Kriegner, E. Wintersberger, J. Stangl, xrayutilities : a versatile tool for reciprocal space conversion of scattering data recorded with linear and area detectors, J. Appl. Crystallogr. 46 (2013) 1162-1170. doi:10.1107/S0021889813017214.

[47] A. Schenk, G. Heiser, Modeling and simulation of tunneling through ultra-thin gate dielectrics, J. Appl. Phys. 81 (1997) 7900-7908. doi:10.1063/1.365364.

[48] S. Witanachchi, H. Abou Mourad, P. Mukherjee, Anomalous metal-to-insulator transition in FeSi films deposited on SiO 2/Si substrates, J. Appl. Phys. 99 (2006). doi:10.1063/1.2185831.

[49] A.Y.C. Yu, Electron tunneling and contact resistance of metal-silicon contact barriers, Solid. State. Electron. 13 (1970) 239-247. doi:10.1016/0038-1101(70)90056-0.

[50] L. Huang, B. Liu, Q. Zhu, S. Chen, M. Gao, F. Qin, D. Wang, Low resistance Ti Ohmic contacts to $4 \mathrm{H}-\mathrm{SiC}$ by reducing barrier heights without high temperature annealing, Appl. Phys. Lett. 100 (2012) 1-5. doi:10.1063/1.4730435.

[51] H.B. Michaelson, The work function of the elements and its periodicity, J. Appl. Phys. 48 (1977) 4729-4733. doi:10.1063/1.323539.

[52] A.M. Cowley, S.M. Sze, Surface States and Barrier Height of Metal- Semiconductor Systems, J. Appl. Phys. 36 (1965) 3212-3220. doi:10.1063/1.1702952.

[53] Y. Fujisaki, T. Ando, H. Kozuka, Y. Takano, Characterization of tungsten- related deep 
levels in bulk silicon crystal, J. Appl. Phys. 63 (1988) 2304-2306. doi:10.1063/1.341045.

[54] T. Ando, S. Isomae, C. Munakata, T. Abe, Deep-level transient spectroscopy on p-type silicon crystals containing tungsten impurities, J. Appl. Phys. 70 (1991) 5401-5403. doi:10.1063/1.350196.

[55] A. De Luca, A. Portavoce, M. Texier, C. Grosjean, N. Burle, V. Oison, B. Pichaud, Tungsten diffusion in silicon, J. Appl. Phys. 115 (2014) 013501. doi:10.1063/1.4859455.

[56] T. Kajikawa, K. Shiraishi, T. Sugiyama, M. Omori, T. Hirai, Thermoelectric properties of high temperature transition metal silicides prepared by spark plasma sintering method, in: Eighteenth Int. Conf. Thermoelectr. Proceedings, ICT'99 (Cat. No.99TH8407), IEEE, 1999: pp. 601-604. doi:10.1109/ICT.1999.843461.

[57] R.T. Tung, The physics and chemistry of the Schottky barrier height, Appl. Phys. Rev. 1 (2014). doi:10.1063/1.4858400.

[58] G. Srinivasan, M.F. Bain, S. Bhattacharyya, P. Baine, B.M. Armstrong, H.S. Gamble, D.W. McNeill, Tungsten silicide contacts to polycrystalline silicon and silicon-germanium alloys, Mater. Sci. Eng. B. 114-115 (2004) 223-227. doi:10.1016/j.mseb.2004.07.019.

[59] D.L. Brors, Low Resistivity Tungsten Silicon Composite Film, 4,851,295, 1989.

\section{List of Figures}

Figure 1: Schematic sequence of the fabrication steps of W structures on Si substrate (not in scale). A thick photo resist was spin coated on a clean Si (001) surface. Then by optical lithography, rectangular patterns were defined in the photo resist, at different distances for TLM measurements. Without removing the native oxide, $100 \mathrm{~nm}$ of $\mathrm{W}$ film was deposited by PLD. Finally, a lift off process in acetone solution to remove the resist mask was used.

Figure 2: Planar view SEM images of $\mathrm{W}$ film $100 \mathrm{~nm}$ thick deposited by PLD. As deposited a), after annealing at: $\left.450^{\circ} \mathrm{C} \mathrm{b}\right), 850^{\circ} \mathrm{C}$ c) and $1000^{\circ} \mathrm{C} \mathrm{d}$ ). The film roughness increases as the temperature increases due to the formation of silicides.

Figure 3: XRR analysis of a $50 \mathrm{~nm} \mathrm{~W}$ film deposited on $\mathrm{Si}$, as compared to a dynamical simulation of a $52.5 \mathrm{~nm}$ film with $0.9 \mathrm{~nm}$ surface roughness (offset vertically for clarity).

Figure 4: XRD analysis of $\mathrm{W}$ on $\mathrm{Si}$ for various annealing temperatures. (a) a grazing incidence $\left(\omega=5^{\circ}\right)$ scan with an "open" detector (acceptance of approximately $\left.2^{\circ}\right)$ gives an overview of the film properties. Following annealing at $450^{\circ} \mathrm{C}$ the film is very similar to the as-deposited material (not shown). Following annealing at $850^{\circ} \mathrm{C}$, the film transforms completely to $\mathrm{WSi}_{2}$ with no carbides or oxides of tungsten visible. The $2 \theta-\omega$ scan (b) around the $\alpha-W(110)$ peak was performed in "tripleaxis" mode with an analyzer crystal in front of the detector, and with this increased resolution and signal-to-noise ratio it is possible to see a weak broad peak (at $47^{\circ}$ ) possibly corresponding to the presence of a small amount of $\mathrm{WO}_{3}$.

Figure 5: SAM depth profiling, across the W-Si interface, of $100 \mathrm{~nm}$ thick $\mathrm{W}$ on Si films deposited by PLD at RT and not annealed. Relative elemental composition is reported, and the oxygen content is also traced. An intermixing W-Si zone ranging $20-30 \mathrm{~nm}$ is evident. The detection of contaminant oxygen does not correspond to any oxidation of the $\mathrm{Si}$, as explained in the text. The minimum 
detectable value in concentration corresponds to $2-5 \%$ sensitivity in detecting elemental composition, under present experimental conditions. The detected Auger spectrum of the Si peak at $96 \mathrm{eV}$ is shown in the inset.

Figure 6: Relative W/Si composition, across the W-Si interface, for $100 \mathrm{~nm}$ thick $\mathrm{W}$ on $\mathrm{Si}$ films, deposited by PLD. Comparison between the composition in as-deposited film and after 5 min RTA step at $850^{\circ} \mathrm{C}$ is shown. The existence of an intermixed W-Si zone below the Si surface is common to both configurations, the extension and composition of which is not affected by RTA step. The RTA-processed sample shows a reduced W/Si ratio in the thickness of the $\mathrm{W}$ coating, indicating the thermally activated inter-diffusion of Si towards the surface.

Figure 7: a) Experimental I-V characteristic measured on a resistor of the TLM structure (electrodes separation $=25 \mu \mathrm{m})$. The linear fit made on this curve report a R-square value of $0.99983 . \mathrm{b}$ ) Simulated IV characteristic of a one-dimensional $\mathrm{W} / \mathrm{SiO}_{2} / \mathrm{Si}$ contact (area $200 \mu \mathrm{m} \times 48 \mu \mathrm{m}$ ) for different values of the native oxide thickness $\left(t_{\mathrm{ox}}\right)$.

Figure 8: a) The I-V characteristics of the TLM resistor at the different annealing temperature ranging from $200^{\circ} \mathrm{C}$ to $1000^{\circ} \mathrm{C}$. b) Specific contact resistivity as a function of the annealing temperature.

Figure 9: Energy band diagram of a metal n-type semiconductor junction at equilibrium, in the Schottky limit and related ohmic conduction models. (a): The voltage barrier $\phi_{B n}$ is formed as a function of the difference between the metal work function and the electron affinity for the semiconductor; (b): Very high doping : $\frac{E_{00}}{k T} \gg 1$, Field Emission (FE) conduction regime through quantum tunneling; (c): Light doping : $\frac{E_{00}}{k T} \ll 1$, Thermionic Emission (TE) regime; (d): Intermediate doping : $\frac{E_{00}}{k T} \sim 1$ Thermionic Field Emission (TFE) regime.

\section{List of Tables}

Table 1: contact resistance values of W-on-Si ohmic contacts obtained with PLD and other deposition techniques after different annealing treatments.

Table 2: Barrier height values calculated in the TFE approximation of the $\mathrm{W}$ on Si contacts varying annealing temperature. 
Table 1

\begin{tabular}{|c|c|c|c|c|c|}
\hline Deposition & \multicolumn{3}{|c|}{ Annealing } & \multirow[t]{2}{*}{$\rho_{c}\left(\Omega \mathrm{cm}^{2}\right)$} & \multirow[t]{2}{*}{ Ref. } \\
\hline & Process atmosphere & Dwell time & Temp. $\left({ }^{\circ} \mathrm{C}\right)$ & & \\
\hline PLD & $\mathrm{N}_{2}$ & $5 \mathrm{~min}$ & 200 & $10^{-2}$ & This work \\
\hline PLD & $\mathrm{N}_{2}$ & $5 \mathrm{~min}$ & 450 & $10^{-3}$ & This work \\
\hline PLD & $\mathrm{N}_{2}$ & $5 \mathrm{~min}$ & 850 & $4 \times 10^{-4}$ & This work \\
\hline $\begin{array}{l}\text { FIB assisted } \\
\text { deposition }\end{array}$ & -- & -- & -- & $10^{-2}$ & [20] \\
\hline $\begin{array}{l}\text { FIB assisted } \\
\text { deposition }\end{array}$ & $90 \% \mathrm{~N}_{2}, 10 \% \mathrm{H}_{2}$ & $15 \mathrm{~min}$ & 450 & $1 \times 10^{-4}$ & [20] \\
\hline $\begin{array}{l}\text { FIB assisted } \\
\text { deposition }\end{array}$ & $90 \% \mathrm{~N}_{2}, 10 \% \mathrm{H}_{2}$ & $20 \mathrm{~min}$ & 400 & $1 \times 10^{-3}$ & [19] \\
\hline$\frac{\text { RF- }}{\text { Sputtering }}$ & -- & -ב- & - & $(3-6) \times 10^{-6}$ & {$[11]$} \\
\hline$\frac{\text { RF- }}{\text { Sputtering }}$ & $\begin{array}{c}\underline{\mathrm{H}}_{2} \text { or vacuum } \\
\left(10^{-7} \text { Torr }\right)\end{array}$ & $\underline{60 \mathrm{~min}}$ & $\underline{700}$ & $(1.5-2) \times 10^{-6}$ & {$[11]$} \\
\hline $\mathrm{CVD}^{(*)}$ & $\underline{\mathrm{N}_{2}}$ & $\underline{60 \mathrm{~min}}$ & $\underline{600}$ & $3 \times 10^{-7}$ & [26] \\
\hline CVD $^{(*)}$ & -- & -- & $\underline{500-550}$ & $2 \times 10^{-8}$ & [59] \\
\hline
\end{tabular}

(*) dopant concentration $10^{20} \mathrm{~cm}^{-3}$

Table 2

\begin{tabular}{ccc}
\hline$\underline{\text { Annealing T }\left({ }^{\circ} \mathbf{C}\right)}$ & $\boldsymbol{\rho}_{\mathbf{C}}\left(\boldsymbol{\Omega} \cdot \mathbf{c m}^{2}\right)$ & $\boldsymbol{\phi}_{\boldsymbol{B n}}(\mathrm{eV})$ \\
\hline$\underline{0}$ & $\underline{2.2 \times 10^{-2}}$ & $\underline{0.48}$ \\
\hline$\underline{200}$ & $\underline{1.8 \times 10^{-2}}$ & $\underline{0.47}$ \\
$\underline{450}$ & $\underline{1.0 \times 10^{-3}}$ & $\underline{0.35}$
\end{tabular}




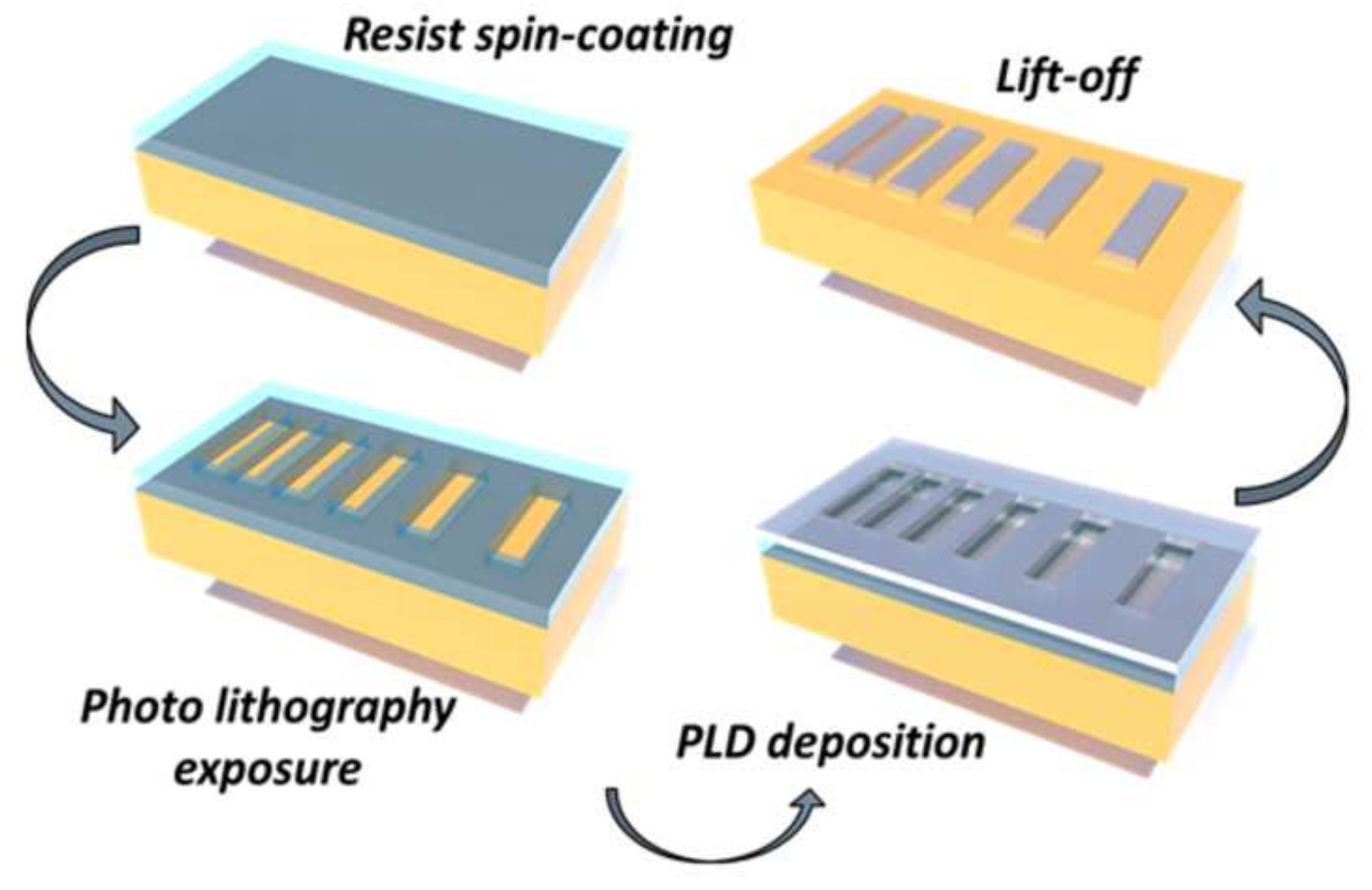
exposure

\section{PLD deposition}

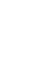

Resist spin-coating 
Click here to download high resolution image

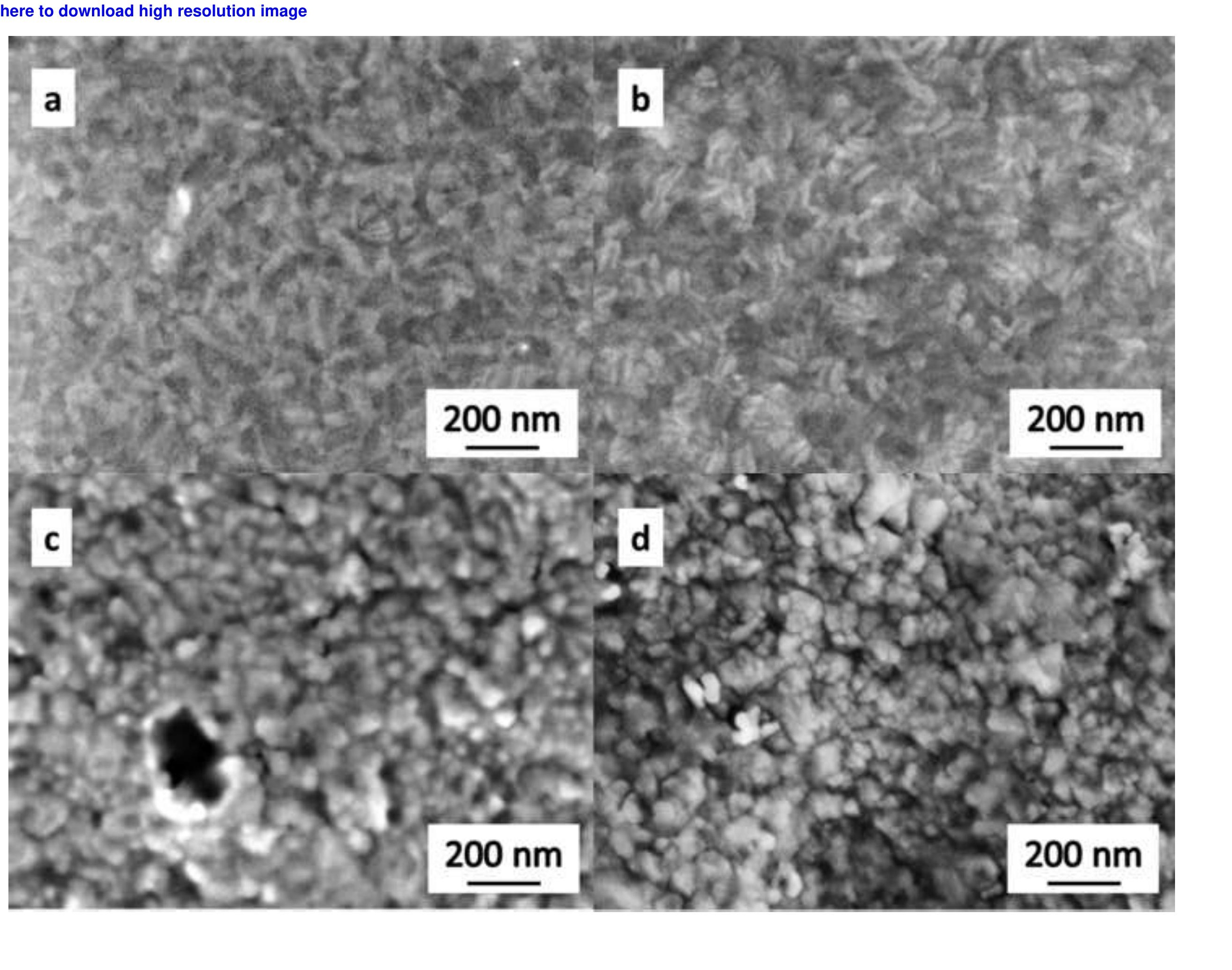

\section{$200 \mathrm{~nm}$}

$200 \mathrm{~nm}$

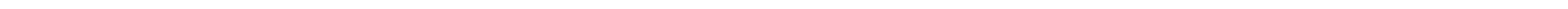
.

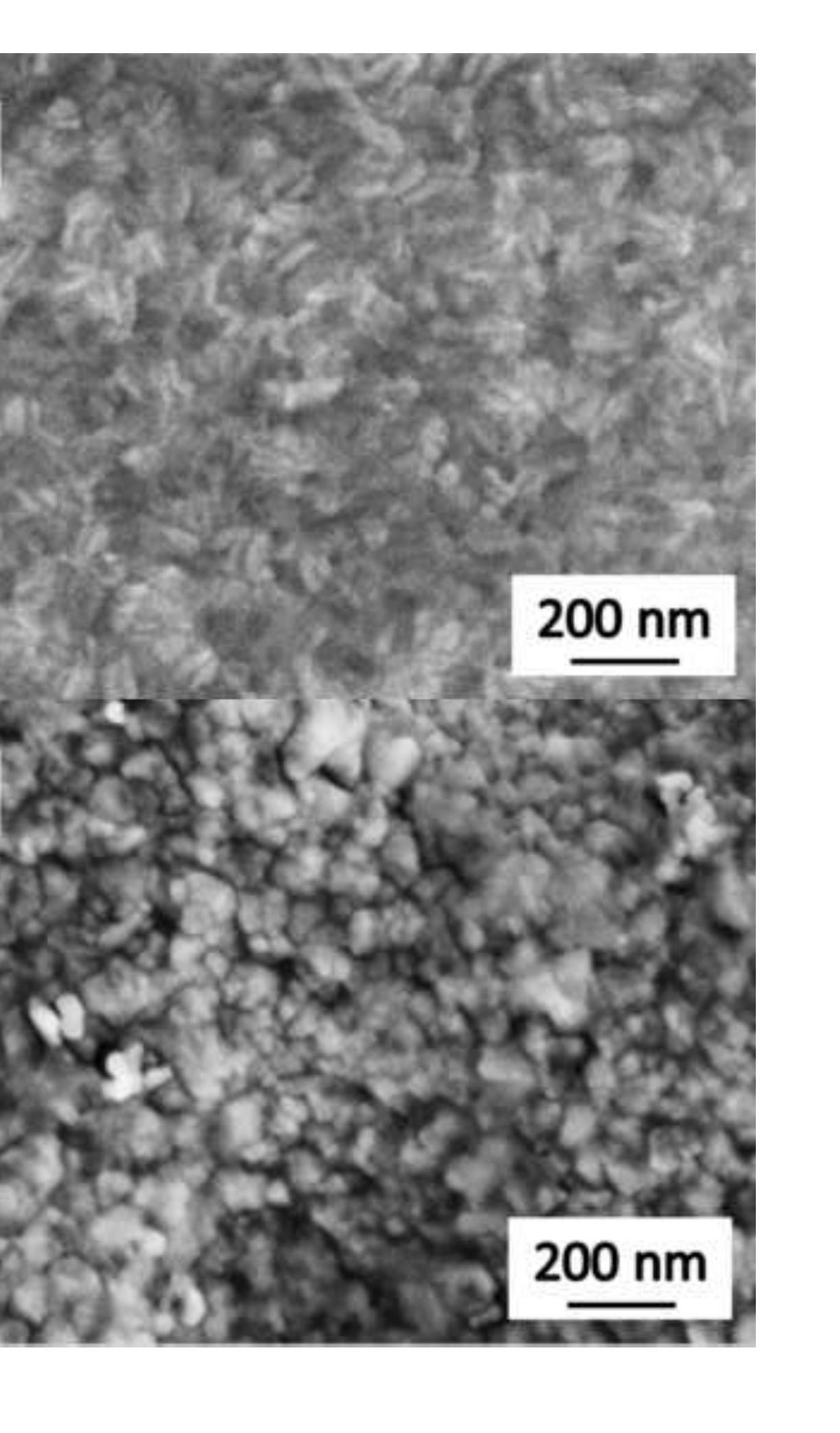


Click here to download high resolution image

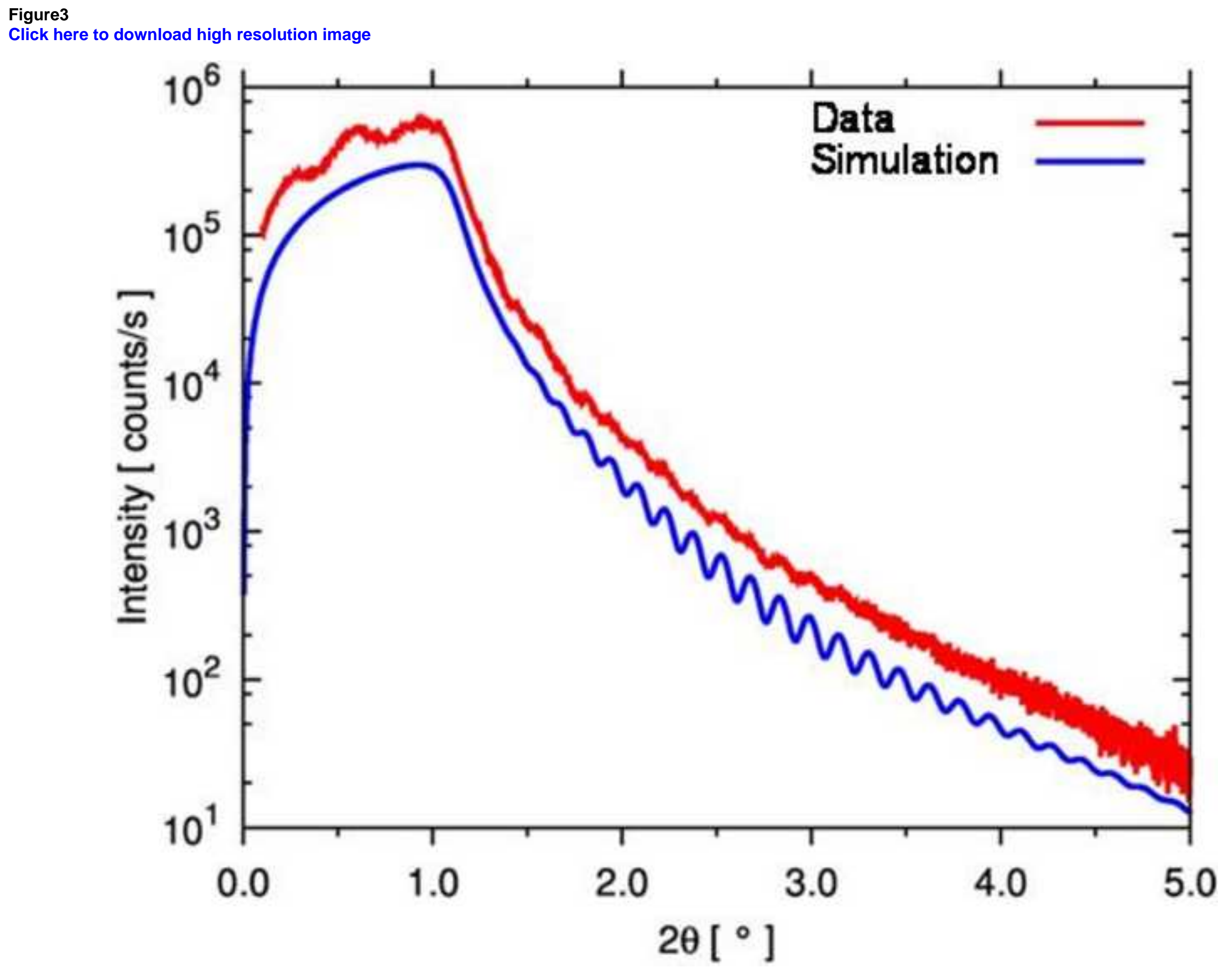



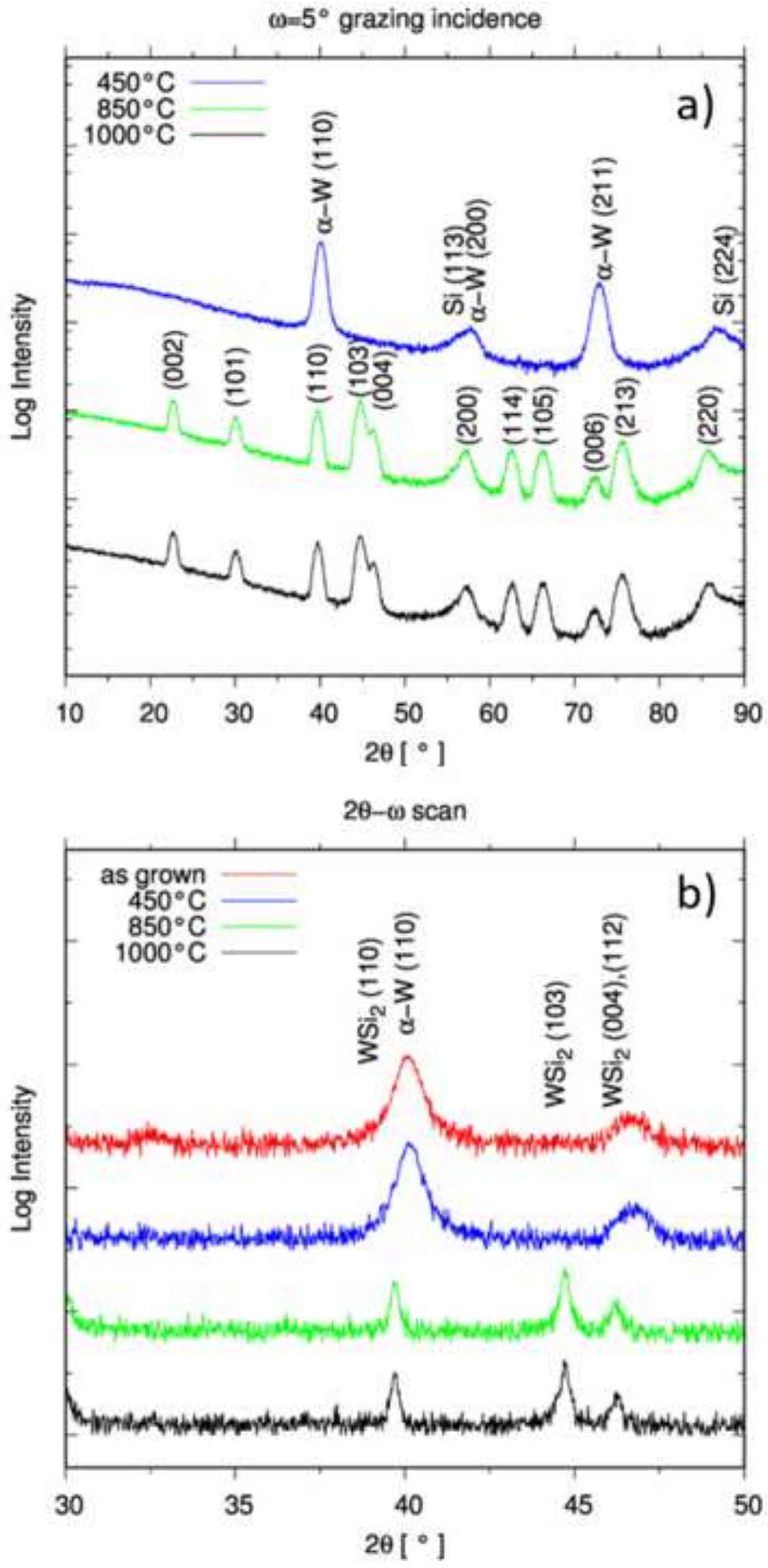

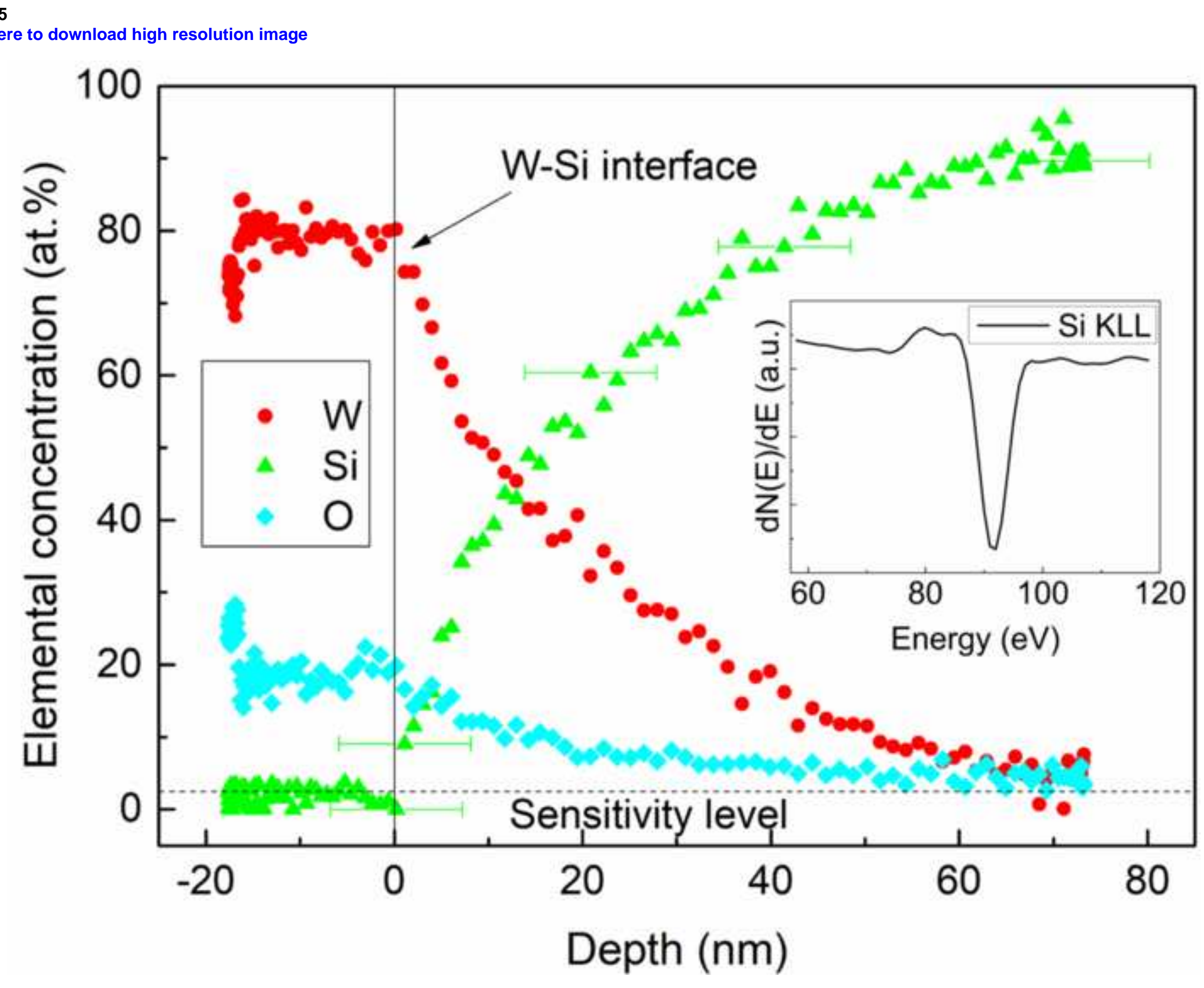

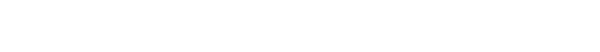




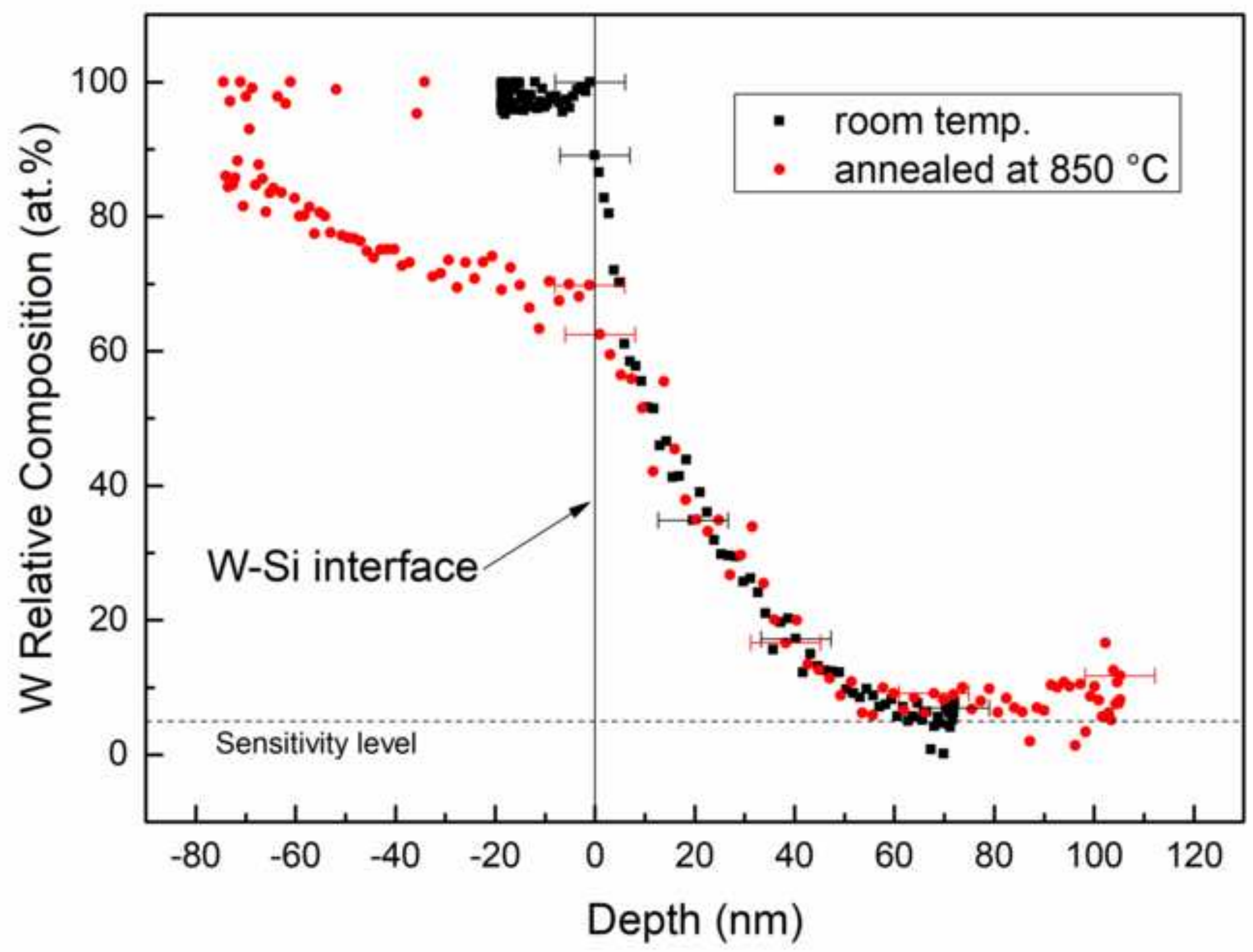



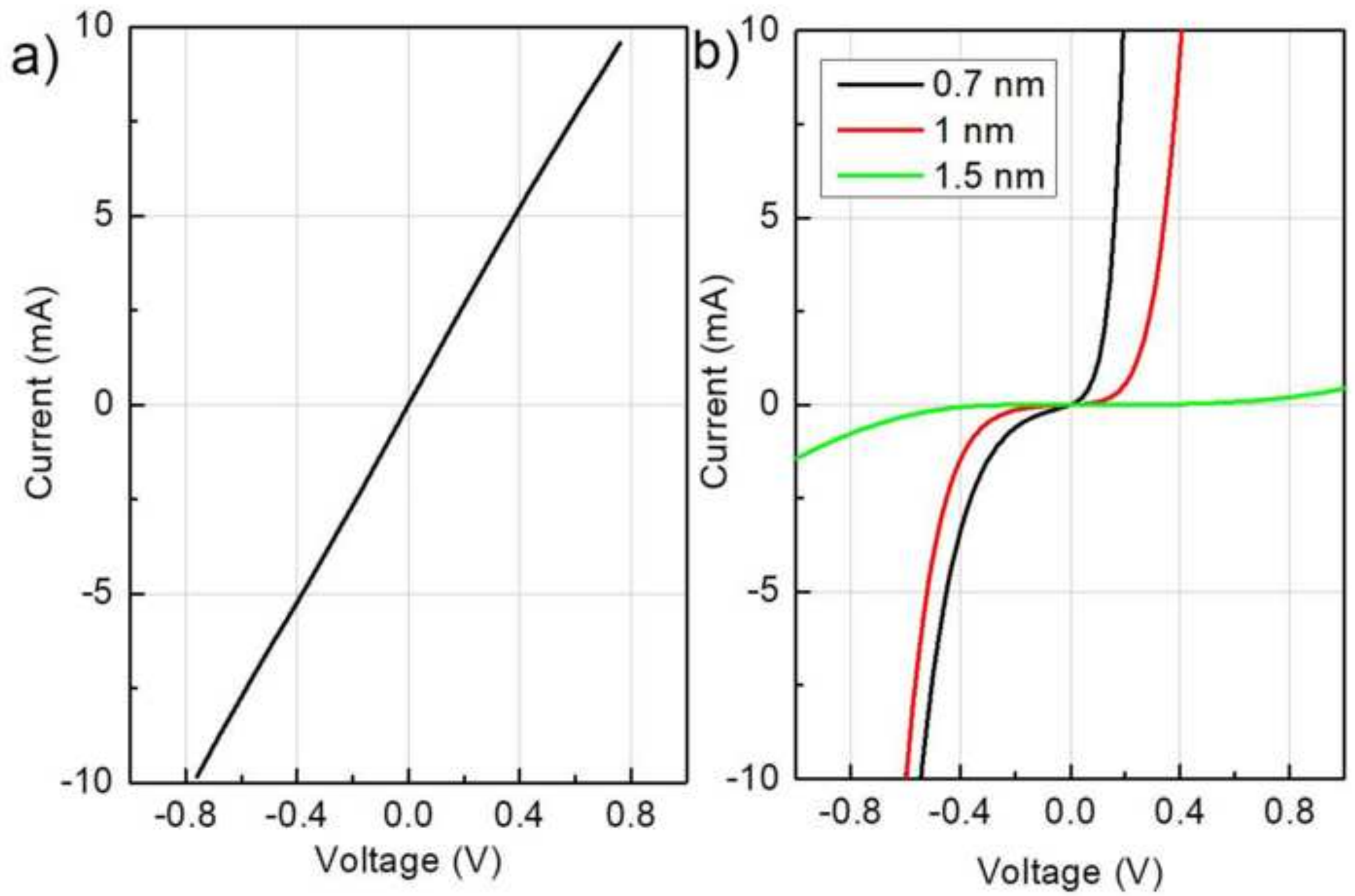
a) 10.0

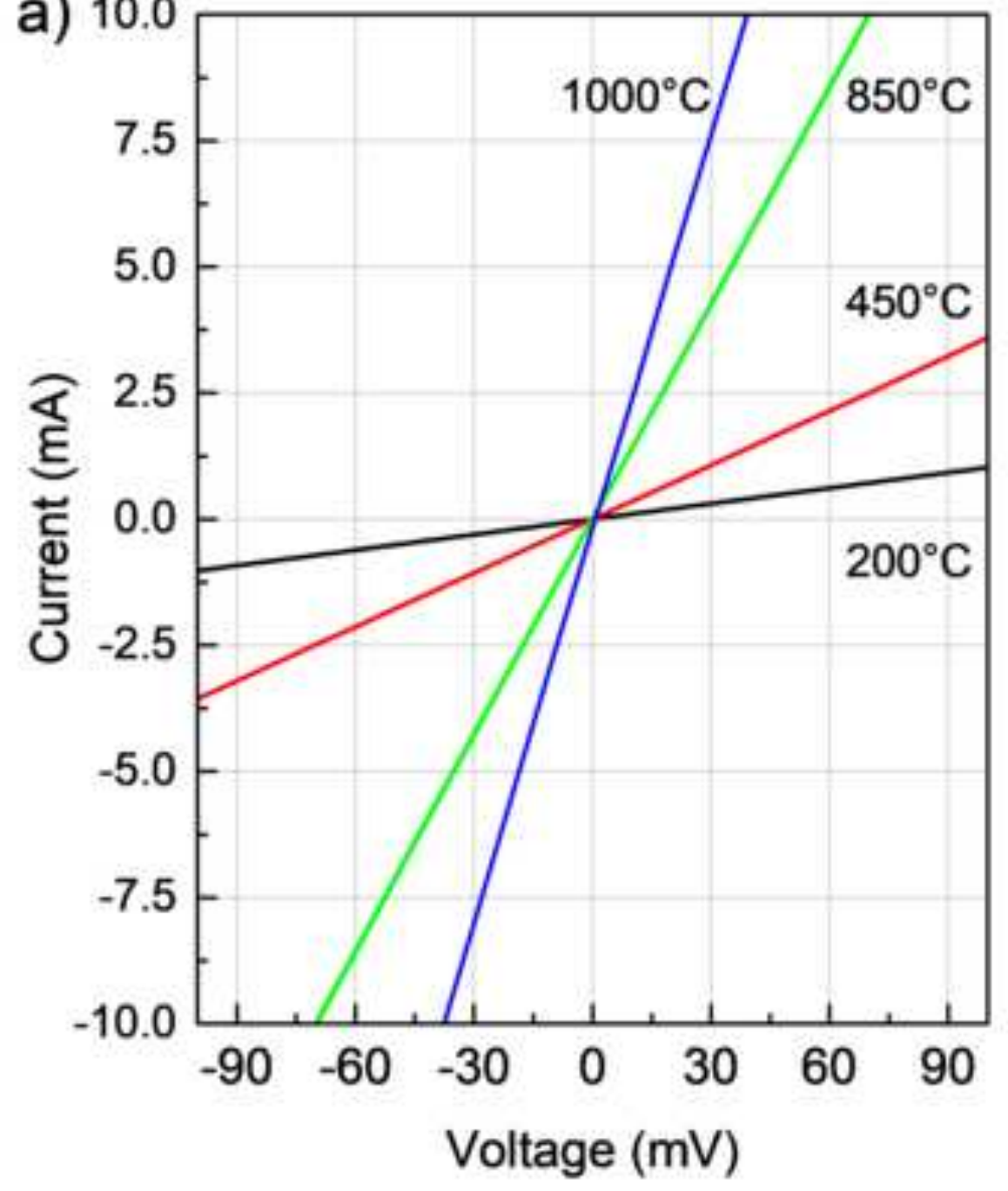

b)

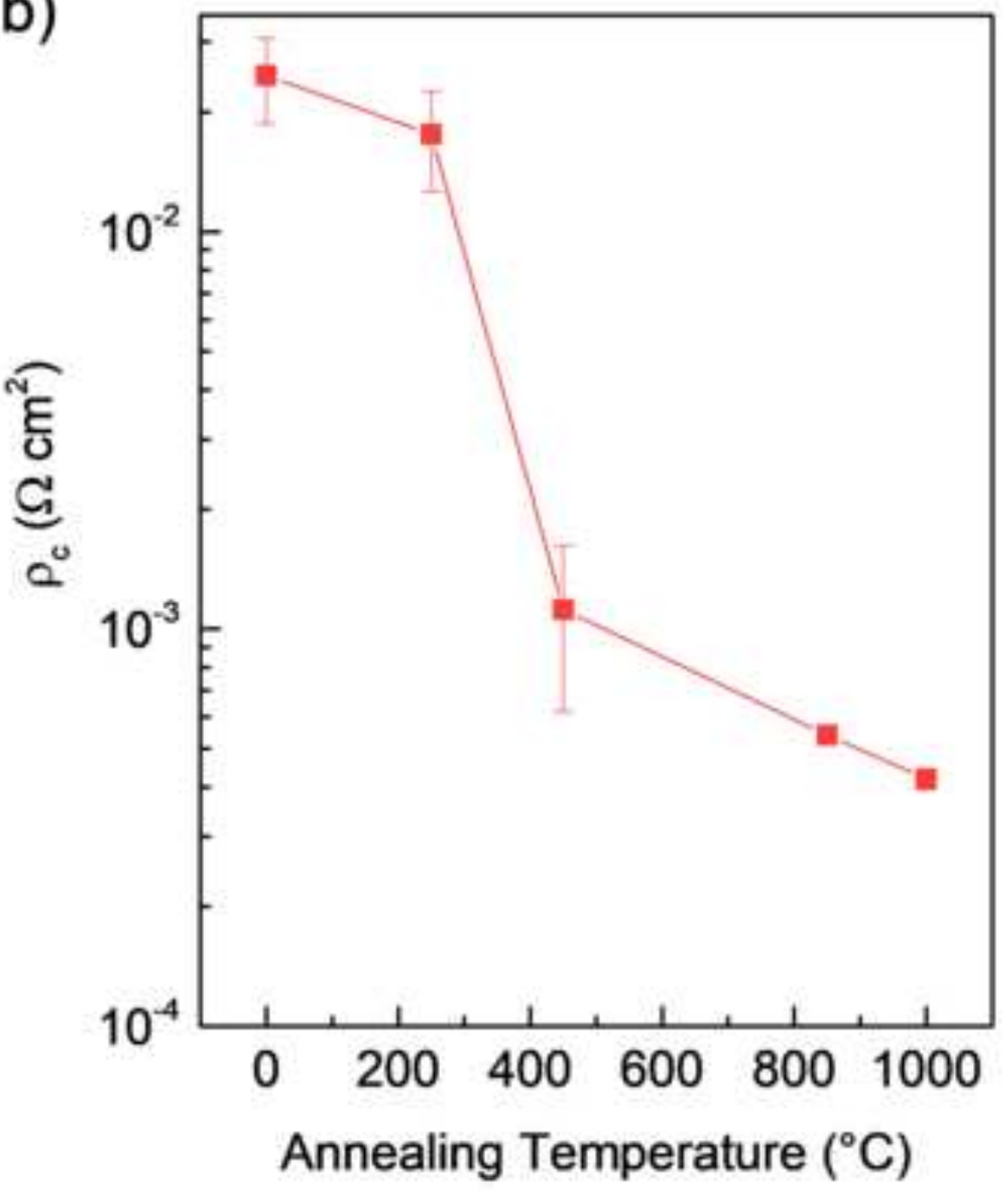



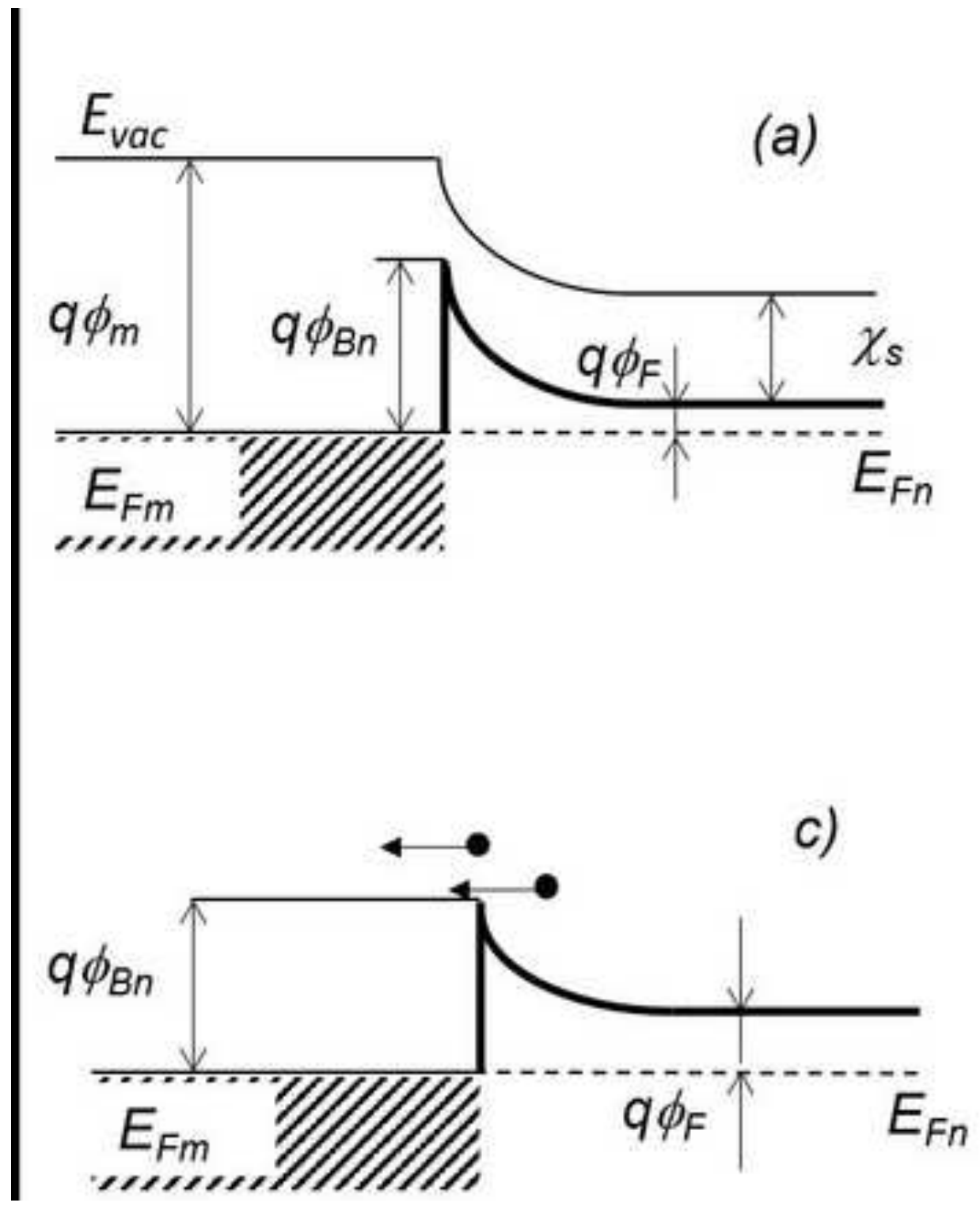
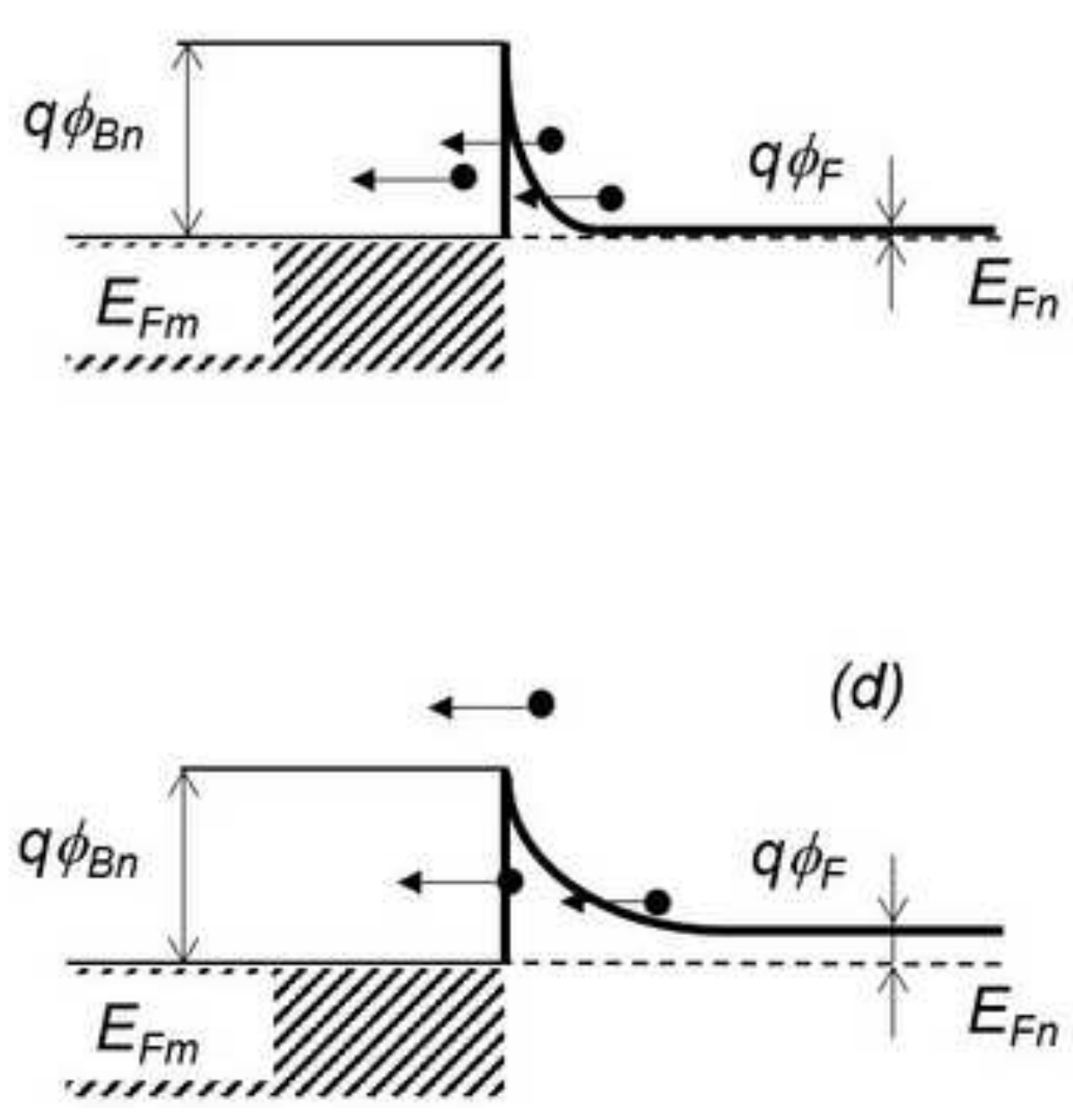

(b) 